\title{
Perioperative personal protective equipment stewardship (POPPiES)
}

\author{
Maha Al Mandhari, MD, MB • Monica Caldeira, PhD • Michelle Dickinson • \\ Conor Mc Donnell, MD, MB
}

Received: 15 April 2020/Accepted: 16 April 2020/Published online: 29 April 2020

(C) Canadian Anesthesiologists' Society 2020

\section{To the Editor,}

The coronavirus disease (COVID-19) pandemic has caused a global shortage of personal protective equipment (PPE). ${ }^{1}$ Meticulous monitoring of use and innovative approaches to allocation are required..$^{2}$ Institutions must quickly develop tracking and conservation strategies to ensure continued protection of healthcare workers. ${ }^{3} \mathrm{We}$ present a stewardship process for N95 mask and respirator allocation that can be rapidly expanded to include all PPE.

Our initiative involved Perioperative Services at the Hospital for Sick Children, Toronto, Ontario. Approval of SickKids Research Ethics Board was not required as no personal health information was accessed. No monitoring of PPE use was present at baseline, and no standardized PPE conservation plans were in place. On 31 March 2020, we developed a database of masks, face shields, and visors used by all perioperative healthcare personnel. Personal protective equipment data were collected per procedure. Isolation precautions and COVID-19 status (positive, negative, possible) were recorded. We instituted a rapid series of Plan-Do-Study-Act (PDSA) cycles to optimize mask distribution, recording, and reporting with a view to future expansion for gowns, gloves, and other important equipment (Figure). Our goal was to integrate perioperative consumption and supply data with hospital daily store reports. Success would be determined by adequate supply

M. A. Mandhari, MD, MB - M. Caldeira, $\mathrm{PhD}$

C. M. Donnell, MD, MB ( $\triangle)$.

Department of Anesthesia \& Pain Medicine, Hospital for Sick Children, University of Toronto, Toronto, ON, Canada

e-mail: conor.mcdonnell@sickkids.ca

\section{Dickinson}

Perioperative Services, Hospital for Sick Children, Toronto, ON, Canada of N95 respirators, early identification of local shortages, prompt response to restock items, lack of equipment diversion, and consistency of data collected.

Root-cause analysis and diagnostics on the first PDSA cycle identified that six different distribution points allowed individuals to acquire multiple masks from separate sources. Despite hospital-wide mandatory fittesting, few operating room (OR) staff knew or recalled their N95 fit size. Clear guidance for PPE requirements relative to case or COVID-19-risk stratification was lacking.

Our team was assembled within $24 \mathrm{hr}$ from local safety coaches, nurse educators, supply managers, and a research coordinator. Our process delivered $>95 \%$ compliance in data recording sustained by the project team. Implemented strategies included:

1. Daily unit huddles with multidisciplinary case-based consensus for PPE use ${ }^{4,5}$ and aerosol-generation as primary discussion points.

2. Daily consumption data identified that $3 \mathrm{M} 8210$ (3M Canada, London, ON, Canada) accounted for 55$62.5 \%$ of daily N95 use. In week one, mean daily 8210 respirator use was 21 masks, increasing to 33 in week two with changing case complexities. When compared with local and hospital inventory, 8210 supplies would have lasted 4.3 to 6.6 days. We procured extra 8210 supplies from hospital stores based on case-scheduling for the upcoming week.

3. Future consumption by case complexity was modelled.

4. Minimum ongoing N95 requirements were calculated taking into account possible reallocation and redistribution of N95 equipment within and between hospitals 


\section{PeriOperative PPE Stewardship (POPPiES)}

\section{part 1 Streamline distribution and limit locations}

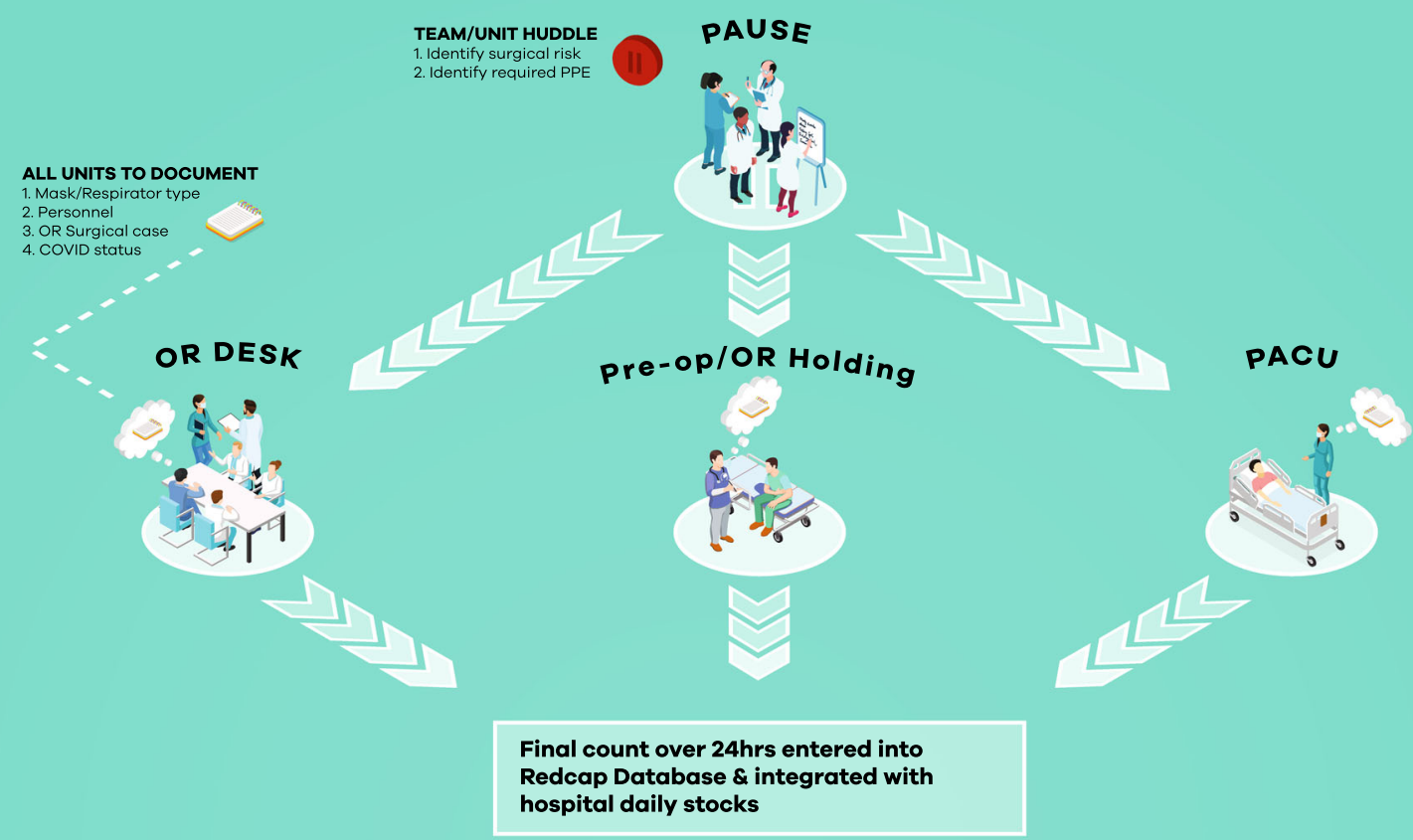

part 2 Guidelines as per CAS, WHO and local IPAC recommendation
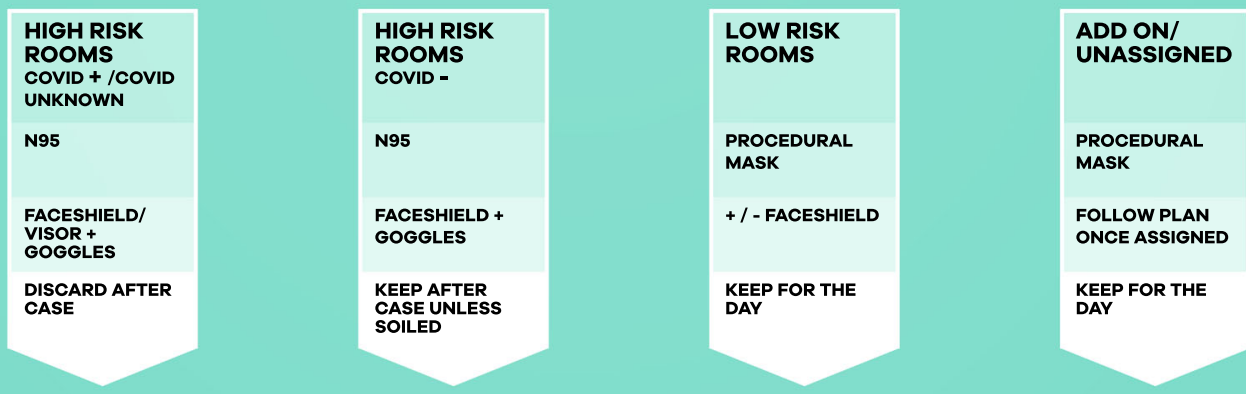

part 3 Trigger early warning shortage and schedule OR staff based on PPE availability
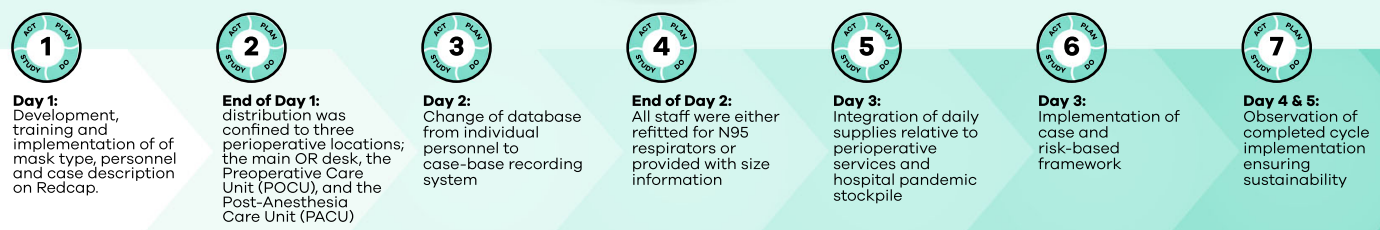
४FIGURE Perioperative PPE stewardship (POPPiES). Part 1 Streamline distribution and limit location. Part 2 Guidelines as per CAS, WHO, and local IPAC recommendation. Part 3 Trigger early warning shortage and schedule OR staff based on PPE availability. CAS = Canadian Anesthesiologists' Society; COVID = coronavirus disease; IPAC = infection prevention and control; OR = operating room $; \mathrm{PPE}=$ personal protective equipment; $\mathrm{WHO}=$ World Health Organization

5. “At risk" PPE items were identified. For example, hospital reports showed a two-day remaining supply of visors (full face shields) during week one. We redirected users to alternative PPE, allowing local supply management to advocate for and procure extra stock from hospital supplies, and conserve low supplies of essential equipment for high-risk airway surgeries the next day.

6. New equipment e.g., reusable visors, re-sterilized masks, etc. were prospectively tracked.

7. Overcrowding at OR desk, and delay in 8 a.m. start times was mitigated by training more OR desk staff and encouraging earlier staffing assignments and safety huddles. OR start times were staggered $15 \mathrm{~min}$ apart to facilitate N95 distribution without violating physical distancing expectations.

8. Colleagues were reassured by evidence-based advice in the face of ever-changing guidelines and mandates from provincial and ministerial sources.

We report the utility of iterative PDSA testing for rapidly establishing PPE stewardship in uncertain times. This model facilitates optimal PPE availability relative to procedure (not provider), allows for preparation of PPE kits for emergency response teams, will continue to inform case/staff scheduling, and promotes confidence in staff safety.

Acknowledgements The authors are grateful for the hard work and commitment of all nurses, clerks, and managers in Perioperative Services at the Hospital for Sick Children, in particular, Jenna Paulo, Jessica Gunawan, Kara Manning, Vivienne Coutu, Chantal Chea, Clare McNeil, Karen Clarke, My Pham, Irina Baranova, Ann Roche, Andrea Sepa, and Lisa Pendergast.
Conflict of interest None.

Funding statement None.

Editorial responsibility This submission was handled by Dr. Gregory L. Bryson, Deputy Editor-in-Chief, Canadian Journal of Anesthesia.

\section{References}

1. World Health Organization. Advice on the use of masks in the community, during home care and in healthcare settings in the context of the novel coronavirus $(2019-\mathrm{nCoV})$ outbreak: interim guidance, 29 January 2020. Geneva: World Health Organization; 2020 (WHO/nCov/IPC_Masks/2020; Available from URL: https:// www.who.int/docs/default-source/documents/advice-on-the-useof-masks-2019-ncov.pdf (accessed April 2020).

2. World Health Organization. Rational use of personal protective equipment for coronavirus disease (COVID-19): interim guidance. 6 April 2020. WHO/2019-nCov/IPC PPE_use/2020.3. Available from URL: https://apps.who.int/iris/bitstream/handle/10665/ 331695/WHO-2019-nCov-IPC_PPE_use-2020.3-eng.pdf (accessed April 2020).

3. Canadian Anesthesiologists' Society. Position Statement: Ethical Considerations of Personal Protective Equipment (PPE) During Scarcity. Approved 04.07.20. Available from URL: https://www. cas.ca/getattachment/Practice-Resources/COVID-19/COVID-

Position-Statement-PPE-Scarcity-04-20.pdf.aspx?lang=en-US (accessed April 2020).

4. Public Health Ontario. IPAC Recommendations for Use of Personal Protective Equipment for Care of Individuals with Suspect or Confirmed COVID-19 - April 6, 2020. Available from URL: https://www.publichealthontario.ca/-/media/ documents/ncov/updated-ipac-measures-covid-19.pdf?la=en (accessed 15 April 2020).

5. Ontario Agency for Health Protection and Promotion (Public Health Ontario), Provincial Infectious Disease Advisory Committee. Annex B: Best Practices for Prevention of Transmission of Acute Respiratory Infection. Annexed to routine practices and additional precautions in all health care settings. Toronto, ON: Queen's Printer for Ontario; 2013. Available from: https://www.publichealthontario.ca/-/media/documents/bp-preventiontransmission-ari.pdf?la=en (accessed 2020).

Publisher's Note Springer Nature remains neutral with regard to jurisdictional claims in published maps and institutional affiliations. 